\title{
ESPELHO DE UMA FILOSOFIA: A PRESENCA DE HEGEL NAS CLASSIFICAÇÕES DE HARRIS E DEWEY
}

\author{
A PHILOSOPHY'S MIRROR: HEGEL'S PRESENCE IN \\ HARRIS AND DEWEY CLASSIFICATIONS
}

\author{
Veronica de Sá Ferreiraa \\ Rodrigo de Sales ${ }^{b}$
}

\begin{abstract}
RESUMO
Introdução: Criada no século XIX, a Classificação Decimal de Dewey (CDD) carrega em sua estrutura hierárquica imutável o pensamento de sua época. Dentre as diversas fontes que contribuíram para sua concepção, William Torrey Harris é reconhecido pela literatura da Organização do Conhecimento como a mais imediata influência utilizada por Dewey para a criação de seu sistema. Em artigo de 1959, Graziano indica o pensamento de Hegel como o verdadeiro suporte filosófico do esquema de Harris e, consequentemente, de Dewey, questionando o lugar ocupado por Bacon nestes sistemas. Objetivos: Os objetivos desta pesquisa são analisar as influências filosóficas que embasaram a classe Artes de Harris e Dewey, refazendo o percurso de Graziano, a fim de verificar a plausibilidade de sua afirmação e ampliar sua discussão, avançando no debate em prol dos aportes teóricos da CDD. Serão examinados assim, o pensamento sobre Artes que formou as classificações de Bacon, Hegel, Harris e Dewey. Metodologia: Como abordagem metodológica, adotou-se como plano de fundo a observação sob a ótica da dialética histórica-estrutural para dar corpo a uma investigação explicativa e qualitativa, tendo em vista interpretações extraídas de uma análise realizada em quatro classificações distintas. Resultados: Os resultados apontam a presença hegeliana não assumida explicitamente por Harris e Dewey em seus sistemas e ainda pouco estudada no campo da representação da informação no Brasil. Conclusões: Conclui-se, em oposição a Graziano, não ser possível afastar totalmente o pensamento baconiano da estrutura do sistema de Harris, todavia, a presença de Hegel se confirma como a fonte alimentadora do conteúdo da classe Artes.
\end{abstract}

Descritores: Organização do conhecimento. Classificação. Artes.

\footnotetext{
a Mestre em Ciência da Informação pela Universidade Federal Fluminense (UFF). Bibliotecária do Museu de Arte Moderna do Rio de Janeiro. E-mail: saferreira.v@gmail.com.

b Doutor em Ciência da Informação pela Universidade Estadual Paulista (UNESP/Marília). Docente do Departamento de Ciência da Informação da Universidade Federal de Santa Catarina (UFSC). E-mail: saferreira.v@gmail.com.
} 


\section{INTRODUÇÃO}

Segundo a tradição literária referente à história das classificações de bibliotecas, a classificação das ciências proposta por Francis Bacon no século XVII foi a base forte das principais classificações bibliográficas desenvolvidas no século XIX, especificamente nos Estados Unidos, com destaque para as classificações de livros de William Torrey Harris e a Classificação Decimal de Dewey (CDD). (LEIDECKER, 1946; SAYERS, 1955; EATON, 1959; MILLS, 1960; LA MONTAGNE, 1961; BARBOSA, 1969; FOSKETT, 1973; VICKERY, 1980; PIEDADE, 1983; WIEGAND, 1998). Sobre esta consolidada perspectiva, pesam as afirmações destes dois classificacionistas, Harris e Dewey, quereconhecem a influência de Bacon na formação de seus sistemas.

O presente artigo reabre uma discussão neste contexto teóricoque serve de aporte para os estudos das classificações de bibliotecas no ocidente.Investigações realizadas nos Estados Unidos apontam que se por um lado é possível flagrar a hegemonia do crédito dado à classificação de Bacon para as pesquisas relativas às classificações bibliográficas, por outro lado observam-se poucas afirmações que questionem o protagonismo da influência de Bacon nas classificações de bibliotecas, e atribuam a Hegel o fundamento mais marcante nas classificações de Harris e, consequentemente, Dewey (GRAZIANO, 1959; OLSON, 2011).

A historiografia sobre a origem da CDD evidencia que a classificação de Harris foi a que influenciou Dewey mais diretamente, ainda que este não explicite esta informação em seus escritos (LEIDECKER, 1946; WIEGAND, 1998; OLSON, 2011). Harris, por sua vez, carrega em seu sistema o pensamento de Hegel, também sem declarar tal fundamento. Baseado nisto, este artigo toma como ponto de partida e como inspiração para uma análise mais crítica, a afirmação do pesquisador e bibliotecário norte-americano Eugene E. Graziano (1959), que afasta o pensamentode Bacon e insere Hegel como fundamentação filosófica da CDD, via classificação de livros de Harris (1870) - sobretudo no que se refere às subdivisões das Artes. A consideração 
do autor desafia as próprias afirmações de Harris e Dewey que reconhecem suas dívidas a Bacon para formulação de seus sistemas.

Entendendo que a influência de Hegel quase nunca é abordada no ensino e na pesquisa de classificações bibliográficas no Brasil, procura-se aqui examinar mais de perto a pertinência da concepção de Graziano (1959) e avançar um pouco mais na discussão que se refere à classificação dos assuntos atinentes às Artes, tendo como enfoque a classificação de Harris, fonte principal da classificação de Dewey.

Considerando que o texto de Graziano (1959) é praticamente desconhecido na comunidade científica brasileira, adota-se nesta pesquisa uma estratégia semelhante a que foi empregada pelo autor, ou seja, uma análise comparativa entre as divisões de Bacon, Hegel e Harris para a classe de Artes, seguida da observação da classe 700 de Dewey, também dedicada a este campo do saber. Objetiva-se verificar a plausibilidade da influência hegeliana nestes sistemas e avançar a discussão em prol dos aportes teóricos que sustentam o debate a respeito das classificações bibliográficas.

Entende-se que a contribuição para o universo da organização e representação do conhecimento pode se dar também pela rediscussão de abordagens já consolidadas pela área, o que pode propiciar uma ampliação da compreensão teórica das classificações bibliográficas.Cabe ressaltar, inclusive, que o presente artigo discorda de afirmações recorrentes na literatura feitas por renomados teóricos da área, tais como Henry Evelyn Bliss e Ingetraut Dahberg, de que não há base teórica alguma na CDD. Assegurar quea CDD é puramente pragmática e não afeita às teorias é negligenciar a história da construção da referida classificação. $O$ presente trabalho procura mostrar, através da classificação de Harris, a teoria que há na construção das relações dos assuntos na CDD por meio da classe Artes, sem com isso fazer apologia a esta classificação.

\section{CONSTRUÇÃO FILOSÓFICA DE UMA CLASSE: APROXIMAÇÕES POSSÍVEIS}


O estímulo para esta discussão parte do artigo de Graziano (1959), que, valendo-se da classe de assuntos destinada às Artes, levanta evidências que buscam comprovar o pensamento hegeliano como o verdadeiro suporte filosófico do esquema de William Torrey Harris (1835-1909) - e, consequentemente, da Classificação Decimal de Dewey -, afastando Bacon do alicerce de tais classificações.

Foi suposto que os sistemas de Harris e Dewey estavam relacionados à classificação de Francis Bacon. A evidência é fortemente contrária a validade de tal suposição. A evidência é forte, senão conclusiva, de que a filosofia de Hegel é parte integrante da relação ordinal dessas classes e que a demanda por lógica na ordem é satisfeita apenas em termos da filosofia de Hegel. (GRAZIANO, 1959, p. 51-52, tradução nossa).

Aponta-se a classificação de Dewey como consequência de Harris, pois estudos acerca das influências sofridas por Dewey na elaboração de seu sistema evidenciam que a ordem e a lógica de suas classes principais de assunto derivam da classificação de Harris (LEIDECKER, 1946; WIEGAND, 1998; OLSON, 2011).

Para assegurar sua hipótese, Graziano (1959) analisa e compara (Figura 1) as divisões das classes Belas Artes, exatamente como ordenadas nas respectivas classificações de Harris, Hegel e Bacon - como afirma.

Figura 1- Comparação de Graziano.

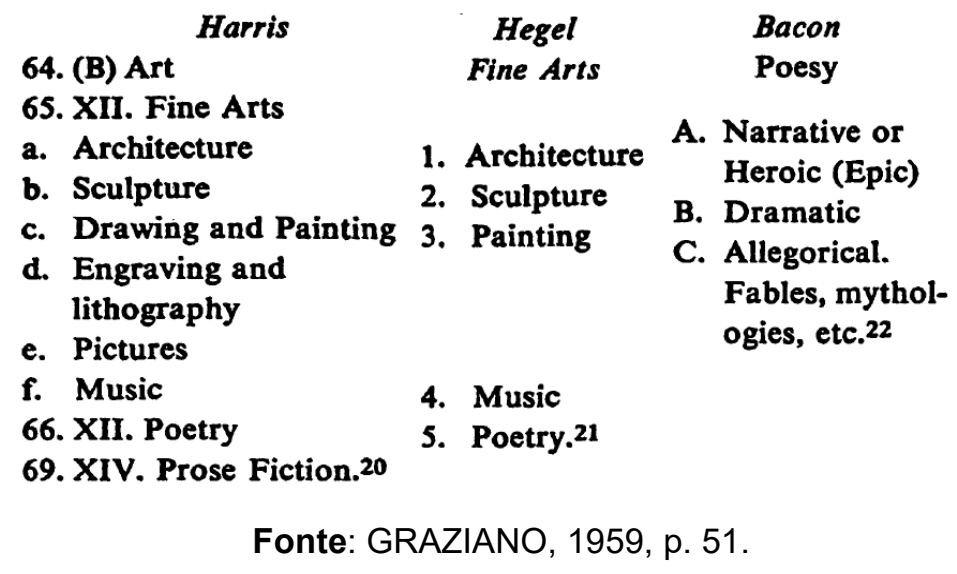

Após analisar mais atentamente o sistema de Bacon, Graziano (1959, p. 51, tradução nossa) estrutura o seguinte questionamento: 
Quando observamos que Bacon fez 'Música' e 'Arquitetura' subclasses de Matemática; e subordina a maior parte das Belas Artes abaixo de 'Filosofia', podemos questionar onde Harris encontrou sua classe. Em Arte, a progressão hegeliana vai da arte mais próxima da matéria, Arquitetura; à Poesia e Prosa, que são as artes 'mais puras', pois estão distantes da matéria e dos sentidos, dependendo quase inteiramente da imaginação. (GRAZIANO, 1959, p. 51, tradução nossa).

O posicionamento de Graziano colide de modo significativo com a tradição literária referente à história das classificações de bibliotecas, que defende o pensamento de Bacon como a influência filosófica que deu suporte à organização de livros nestes espaços. A fundamentação teórica para tal serão as ideias expostas nos livros "O progresso do conhecimento", de Francis Bacon (1605 - edição consultada de 2007), "Curso de Estética: o Sistema das Artes", de G. W. F. Hegel (1835 - edição consultada de 1997), "Decimal Classification and Relative Index", 23a edição, de Melvil Dewey (2011) e o artigo "Book Classification", de William Torrey Harris (1870).

\subsection{A Arte no Progresso do Conhecimento de Bacon}

Dar-se-á início pelo ponto de divergência apontado por Graziano (1959), a classe Poesia elaborada por Bacon e apresentada da seguinte forma:

Figura 2 - Classe Poesia de Bacon. Extrato da comparação de Graziano.

\begin{tabular}{|l|}
\multicolumn{1}{|c|}{ Poesia } \\
\hline A. Narrativa ou Heroica (Épica) \\
B. Dramática \\
C. Alegórica. Fábulas, Mitologias, etc. \\
\hline
\end{tabular}

Fonte: Graziano (1959). Adaptado pelos autores.

Entende-se que Graziano (1959), ao elaborar sua análise comparativa sobre a classe Belas Artes (Figura 1), toma como ponto de partida a posição intermediária que estas classes ocupam nos sistemas de Bacon e Harris. Isto explica porque o autor utilizou como referência para a comparação a Poesia de Bacon, e não a Arte ou os assuntos atinentes à esta que se desmembravam predominantemente na Filosofia (Figura 3). 


\section{Figura 3 - Classificação de Bacon resumida}
History
A. Natural History
a. Generations
b. Praeter
c. Arts
B. Civil History
a. Civil History Proper
b. Ecclesiastical History
c. Literary History
C. Appendix to History
c. Appendix Mathematics
1. Pure Mathematics
2. Mixed Mathematics
(a) Perspectives
(b) Music
(c) Astronomy
(d) Cosmography
(e) Architecture
(f) Mechanics
Poetry
C. Philosophy of Man
a. Human Philosophy
A. Narrative (Epic)
B. Dramatic
C. Allegorical. Fables, Mythologies, etc.
Philosophy
A. Theology or Divine Philosophy
B. Natural Philosophy
a. Speculative
1. Physics
2. Metaphysics
b. Practical
1. Body
(a) Medicinal Arts
(d) Voluptuary
(Liberal) Arts
(1) Painting
(2) Music
2. Soul and Body related
3. Soul
(a) Rational Soul
(1) Faculties:
a) Logic
b) Ethics 8

Fonte: GRAZIANO, 1959, p. 47, grifo nosso.

Em sua obra "O progresso do conhecimento" (1605), Bacon explica as divisões das classes que compõe seu Sistema. Apresenta o que é o conhecimento e como ele deve ser produzido e utilizado enquanto parte do "progresso da humanidade", e traz a classificação dos saberes de maneira detalhada, mapeando as partes do conhecimento, apontando suas condições de desenvolvimento e definindo-as como perfeitas, imperfeitas ou inacabadas. (SHIRAYAMA, 2016).

A classificação de Bacon pretendia ser mais do que uma simples ordenação das ciências, pretendia ser um método, um guia determinante de como o conhecimento deve ser construído. No mapeamento do "aprendizado humano" - como o nomeia -, Bacon estabelece que "as partes do conhecimento humano fazem referência às três partes do entendimento humano, que é a sede do saber: a História à sua Memória, a Poesia à sua Imaginação e a Filosofia à sua Razão" (BACON, 2007, p. 112). Destas três divisões principais se desdobram as classes que compõe a classificação dos saberes, apresentadas de forma resumida na Figura 3.

O século XVII, data da obra de Bacon, caracteriza-se pelo pensamento que reformulou os métodos científicos e o experimentalismo, assegurando à ciência sua plena autonomia a respeito da Teologia e da Filosofia. Bacon "defendia o 
método racional indutivo, alicerçado em bases experimentais, com a ressalva de que fundamentava sua classificação em aspectos de uma consciência subjetiva humana" (SIQUEIRA, 2010, p. 44). A finalidade do conhecimento científico era, portanto, servir o homem e dar-lhe poder sobre a natureza.

Apesar de Graziano (1959) desenvolver sua análise considerando a classe Poesia de Bacon como equivalente a Arte na classificação de Harris tendo em comum a posição intermediária que ocupam em ambos os sistemas - observa-se que a palavra "Arte" aparece duas vezes na classificação de Bacon, como destacado na Figura 3. Cabe aqui analisar tais situações.

A primeira manifestação da palavra (Figura 3) está subordinada à História e relaciona Arte à História da Natureza. Bacon divide a História da Natureza em três: natureza em seu curso normal (história das Criaturas); em seus erros ou variações (história das Maravilhas); alterada ou trabalhada (história das Artes). O filósofo vê a primeira como real e bem feita, mas considera as demais deficientes, pois recebem um tratamento fraco e improdutivo (BACON, 2007).

Quando discorre sobre o último tipo de História da Natureza - a que interessa a esta análise - Bacon acrescenta o termo "Mecânica", passando a ser "História da Natureza Trabalhada ou Mecânica". O filósofo critica o tratamento insuficiente dado a este saber e afirma existir "compilações de agricultura, bem como de artes manuais, mas geralmente com desprezo dos experimentos familiares e vulgares" (BACON, 2007, p. 115). Isto porque era visto com descrédito refletir sobre assuntos mecânicos a não ser que fossem incomuns ou raros. Bacon considera arrogante e fútil este comportamento desdenhoso às questões mecânicas, uma vez que são os exemplos mais simples que proporcionam informações mais seguras e não os mais elevados.

Bacon via o uso da História Mecânica como primordial à filosofia natural, pois beneficiava e enriquecia a vida humana, sugerindo soluções "mediante a conexão e transferência das observações de uma arte à prática de outra [...]" (BACON, 2007, p. 117). Tal conduta proporcionaria "uma iluminação mais verdadeira e real sobre as causas e axiomas que até agora se alcançou" 
(BACON, 2007, p. 117), o que ressalta a crença do filósofo no método empírico-indutivo.

Nota-se que a descrição que o filósofo oferece desta História, refere-se às Artes Mecânicas, posto que são estas as artes pertinentes ao trabalho humano. Segundo Bacon (2002, p. 49), as artes mecânicas "[...] são fundadas na natureza e se enriquecem das luzes da experiência, [...] e essas (desde que cultivadas), como que animadas por um espírito, continuamente se acrescentam e se desenvolvem, de inicio grosseiras, depois cômodas e aperfeiçoadas, e em contínuo progresso".

Antes, vistas como menores e desprestigiadas, as Artes Mecânicas foram resignificas nos séculos XVI e XVII, sendo valorizadas por sua utilidade para o progresso do conhecimento, com destaque sobre seu valor educativo. "Os procedimentos cotidianos dos artesãos, dos engenheiros, dos técnicos, dos navegantes, dos inventores são elevados à dignidade de fato cultural [...]" (ROSSI, 2006, p. 84).

A segunda manifestação da palavra Arte, está subordinada à parte Filosofia. Inserida dentro de Filosofia Humana, as Artes Voluptuárias (Artes Liberais), estão localizadas hierarquicamente abaixo de Corpo na classificação, conforme Figura 3.

Bacon acreditava que a contemplação do homem, na Filosofia, poderia ser dirigida a Deus, à Natureza, ou ao próprio Homem, gerando assim a filosofia Divina, Natural e Humana. Isto porque, "todas as coisas estão marcadas e estampadas com este caráter tríplice: o poder de Deus, a diferença da natureza e a utilidadedo homem" (BACON, 2007, p. 136).

As Artes Liberais fazem parte, na classificação de Bacon, da Filosofia humana, portanto, se voltam ao próprio homem e são úteis a ele. Nesta Filosofia, o indivíduo pode ser visto de forma particular e civil. Para Bacon (2007, p. 163) "a Humanidade Particular se compõe das mesmas partes que o homem, isto é, de conhecimentos relativos ao Corpo e [...] ao Espírito", considerando o corpo tabernáculo do Espírito.

O conhecimento concernente ao corpo humano se divide em quatro classes de acordo com seus bens: Saúde, Beleza, Força e Prazer. Assim, os 
saberes são, respectivamente, "[...] a Medicina ou arte da Cura; a arte do Adorno, que se chama Cosmética; a arte da Atividade, que se chama Atlética; e a arte Voluptuária, que Tácito chama acertadamente eruditus luxus [voluptuosidade refinada]" (BACON, 2007, p. 167).

Bacon insere as Artes Liberais (Artes Voluptuárias) especificamente na quarta classe - Prazer - e afirma que sua principal deficiência é a de leis que a reprimam. Talvez sua crítica se deva ao fato de, atribuindo nova importância às Artes Mecânicas, as Artes Liberais, antes eruditas, tornam-se ilusões.

Finalmente, a Poesia - divisão que Graziano (1959) considera como equivalente à Belas Artes em Harris -, de acordo com Bacon, é "[...] uma parte do saber quase sempre restringida quanto à medida das palavras, mas em todos os demais aspectos sumamente livre" (BACON, 2007, p. 131). Possui o poder de "[...] unir a seu prazer o que a natureza separou, e separar o que a natureza uniu, e desse modo fazer matrimônios ilegais e divórcios das coisas: [...] Os pintores e os poetas sempre tiveram permissão para tomar as liberdades que quisessem" (BACON, 2007, p. 131).

Bacon considera que a Poesia possui dois sentidos: um relacionado às palavras e outro ao conteúdo. O primeiro é, objetivamente, uma característica do estilo e se inclui nas artes retóricas. Sua função é determinar comportamentos, estando rigorosamente ligado à ética (ROSSI, 2006). O segundo constitui "[...] uma das partes principais do saber, e não é outra coisa que história simulada, que pode ser composta tanto em prosa como em verso" (BACON, 2007, p. 131). O filósofo dá ênfase ao segundo sentido e entende que a Poesia, nesta função de história simulada, possui o papel de deleitar, a mente humana quando a natureza das coisas não oferece esta condição.

Bacon (2007, p. 132-133) divide a classe Poesia em três tipos, conforme seu caráter próprio: Narrativa, Representativae Alusiva. A primeira se ocupa em contar a história com as licenças da imaginação, "[...] comumente escolhendo como temas as guerras e os amores, raramente os assuntos de Estado, e ocasionalmente o prazeroso e o cômico". A segunda apresenta a história de forma mais realista, ou seja, "[...] visível, e é uma imagem das ações como se estas estivessem presentes, do mesmo modo que a história o é das 
ações como são na realidade, isto é, passadas". Já a terceira tem como objetivo“[...] expressar algum propósito ou ideia particular”. Bacon (2007) não assinala na Poesia nenhuma deficiência.

Constata-se que, para o filósofo, a Poesia está absolutamente relacionada ao uso da palavra, fazendo parte dela a arte retórica e a história simulada (em prosa e verso). Apesar de afirmar que os pintores e os poetas possuem permissão para realizar o que desejam, Bacon não une Arte e Poesia na posição intermediária de sua classificação dos saberes - como acontece na classificação de Harris. O filósofo apresenta o conhecimento como o final de um processo que passa pela Memória (História), Imaginação (Poesia) e Razão (Filosofia). O lugar central, habitado pela Poesia, tem a função de compreender o repositório de experiências obtido pela História, sendo então processado pela Filosofia, gerando assim o conhecimento.

As Artes Mecânicas e Liberais são contempladas no sistema de Bacon subordinadas à História e à Filosofia, respectivamente. Todavia, suas divisões em nada se assemelham às de Belas Artes determinadas tanto por Hegel quanto por Harris. O mesmo acontece com Poesia, o que confirma, neste ponto, a afirmativa de Graziano (1959) sobre a quase inexistência do pensamento baconiano na classificação de Harris.

\subsection{O Sistema das Artes de Hegel}

Hegel, diferente de Bacon, não estabeleceu formalmente uma classificação das ciências ou dos conhecimentos conforme consagrados à sua época. Para tecer comparação entre as classificações, Graziano (1959) resgatou os cinco gêneros artísticos que Hegel determinou em seu Sistema das Artes (1835), conforme apresentados na Figura 4.

Figura 4 - Divisão das Artes de Hegel. Extrato da comparação de Graziano.

\section{BelasArtes}

1. Arquitetura

2. Escultura

3. Pintura

4. Música

5. Poesia

Fonte: Graziano (1959). Adaptado pelos autores. 
O objetivo de Hegel não era ordenar as ciências de seu tempo decretando-as à "[...] um esquema axiomático de princípios organizadores, préconcebido e exterior, que as trataria enquanto realidades 'imóveis', como se de 'espécies' diferentes se tratasse [...]". Pretendia sim "[...] captar as ciências na sua unidade orgânica, na sua plasticidade dialética, no movimento interno que as anima enquanto partes necessárias de um todo - a filosofia" (POMBO, 2002).

No século XIX - período em que viveu Hegel, Harris e Dewey - a tradição científica europeia parecia aproximar as ciências naturais do desenvolvimento das ciências sociais, evidenciando-se, por exemplo, os trabalhos de Darwin e Comte. Buscava-se compreensão das novas conexões interdisciplinares devido aos grandes descobrimentos das ciências. (ANJOS, 2008; SIQUEIRA, 2010). Neste contexto, a classificação passa a ser o problema central da filosofia das ciências, tentando conciliar o utilitarismo com o positivismo, e Hegel ocupa-se do desenvolvimento de uma ordem lógica para os saberes.

Conforme Anjos (2008, p. 65), a classificação de Hegel "aparece como uma consequência de seu sistema filosófico, ou seja, a classificação emanada de seu pensamento não deriva de uma ideia de desenvolvimento da natureza, senão do espírito como criador da natureza". Seu sistema é especulativo, tritônico e com base na lógica dialética (síntese dos opostos). O saber científico era visto como um conhecimento conceitual e as conexões internas às ciências como ideais.

Nos gêneros estabelecidos por Hegel em seu sistema, Poesia e Arte caminham juntas, todavia, ao incluí-las na comparação, Graziano (1959) não o faz pela posição intermediária que ocupam em uma classificação, e sim por acreditar que seu conteúdo é o que alimenta a classe Belas Artes de Harris.

O livro "Curso de Estética: o sistema das Artes" apresenta tal sistema explicando cada gênero artístico e o posicionamento que ocupa na divisão. Esta obra não é um livro de Hegel, mas uma compilação de seus manuscritos e anotações de seus alunos dos quatro cursos que ministrou em Berlim, de 1820 
a 1828, sobre a Estética. O responsável pela reunião destes textos, em 1835, foi Hotho, aluno de Hegel. (KELLER, 2011).

O Sistema de Hegel ocupa-se em compreender a Estética, o belo na arte. As questões estéticas fundam-se no fracasso histórico das artes poéticas. Segundo Santoro (2007), na história do Ocidente a obra que "[...] mais influenciou a estética tanto no sentido de filosofia da arte, quanto no sentido de produção refletida da obra de arte" foi a Poética de Aristóteles. Valendo-se dessa autoridade, as artes poéticas pretendiam "[...] formular um conceito racional do belo e sobre ele fundar o enunciado dos princípios que regulam necessariamente a elaboração das obras" (BRAS, 1990, p. 16). Todavia, no Renascimento italiano, "[...] pela primeira vez, a pintura e a escultura passaram a ser igualmente consideradas belas artes e a ter um status social de arte livre equivalente ao das artes poéticas". Ampliou-se assim "[...] o que Aristóteles dizia sobre as artes literárias, para aplicar-se à reflexão também das demais artes, inclusive as artes plásticas, que não estavam no escopo original do filósofo" (SANTORO, 2007). A instauração do campo da Estética nos séculos XVIII e XIX afirmou socialmente os cânones, "[...] baseados numa determinada tradição dos modos de enunciação de um discurso racional sobre o belo" (NORONHA, 2005, p. 137).

Hegel (1997, p. 13) aponta que "a verdadeira classificação deve basearse [...] na natureza das obras de arte, a qual esgota no conjunto dos gêneros a totalidade dos aspectos e dos momentos inerentes ao conceito de arte". Sendo assim, cada gênero ocupa uma posição lógica dentro do Sistema.

O primeiro lugar, ocupado pela Arquitetura, a pertence por sua própria natureza. Segundo Hegel (1997, p. 16), a arte tem início por ela, pois em seu princípio, ainda não havia estabelecido, "[...] nem os materiais apropriados nem as formas correspondentes" para representar seu conteúdo espiritual. Isto "[...] a obrigou a limitar-se à simples procura da verdadeira adequação e a contentar-se com o conteúdo e com um modo de representação puramente exteriores".

O segundo lugar corresponde à Escultura. Para Hegel (1997, p. 17), esta forma artística possui seu princípio e conteúdo "[...] representados pela 
individualidade espiritual, tal como ideal clássico, de maneira que a interioridade e a espiritualidade encontrem sua expressão no aspecto corporal imanente ao espírito [...]". Assim como a arquitetura, a escultura faz uso de materiais pesados em sua totalidade espacial, mas nela, a forma determinada pelo conteúdo representa a vida real, ou seja, é a figura humana "[...] que deve ser a representação exterior adequada da independência divina na sua alma grandiosa e na grandeza tranquila, sem se deixar tocar pelas vicissitudes e limitações da ação, por conflitos e sofrimentos".

O terceiro e quarto lugar do Sistema, são ocupados pelas artes que Hegel determina como as últimas "[...] que têm por incumbência exteriorizar a interioridade subjetiva" (HEGEL, 1997, p. 17), são elas: Pintura e Música.

A pintura é o primeiro passo do sensível para se aproximar do espírito. Diferente das outras artes, não manipula materiais pesados, suprimindo a realidade da manifestação sensível àaparência, fazendo uso das cores. A figura exterior torna-se a expressão total do interior, mostrando o absoluto não apenas voltado a si, mas também a "[...] subjetividade espiritual, capaz de ver, de sentir, de agir, de contrair relações com o que é diferente dela, e, por conseguinte, exposta à dor, ao sofrimento, acessível, a todas as paixões e a todas as satisfações" (HEGEL, 1997, p. 17-18).

A música, diferente da pintura, não possui forma. "O seu elemento próprio é a interioridade como tal [...] que se manifesta não na realidade exterior, mas por uma exteriorização instantânea que se desvanece logo que é surpreendida" (HEGEL, 1997, p. 18). A subjetividade espiritual, na sua unidade imediata, é o que estabelece seu conteúdo. Utiliza como materiais "[...] os sonse as suas figurações, os seus acordes e separações, as suas combinações, oposições, contradições e meditações, segundo as suas diferenças quantitativas e as suas durações submetidas a medidas especiais, elaboradas com método". A arte permite que a alma humana absorva música como sentimento puro, desprendida de um suporte.

O gênero que segue a pintura e a música e ocupa o último lugar no Sistema das Artes é a Poesia. Descrita por Hegel (1997, p. 18) como a arte da palavra, é compreendida por ele como a "[...] verdadeira arte absoluta do 
espírito manifestando-se como espírito". Por sua forma de representação, o filósofo considera a Poesia como a arte total ou a arte em si, pois a palavra é a única com a capacidade de "[...] se apropriar, de exprimir, transformando-o [espírito] em objeto de representação, tudo quanto a consciência concebe e reveste de uma forma que ela encontra em si própria".

A Poesia vence sob o ponto de vista espiritual, sendo a arte mais rica e ilimitada, mas perde sob o sensível, pois é desprovida "[...] de toda a existência sensível na qual o espírito possa encontrar a forma sensível que lhe convém" (HEGEL, 1997, p. 19), como fazem as demais artes do Sistema. A Poesia "[...] procura somente tornar acessíveis à intuição e à representação espirituais as significações revestidas de uma forma de proveniência puramente interior".

Ou seja, por utilizar a palavra, a Poesia está menos presa ao sensível tornando-se mais espiritual, sendo "entendida não apenas como a arte mais elevada, mas também como 'última' expressão artística, já que no desenrolar dialético da esfera do espírito absoluto a próxima estação já se encontra para além do âmbito artístico [...]" (DUARTE, 2016, p. 5).

Estas cinco artes formam "[...] o sistema definido e articulado da arte real e efetiva. Existem certamente, além destas, outras artes, tais como a dança, a arte dos jardins etc., mas artes incompletas" (HEGEL, 1997, p. 20).

Vale ressaltar que, apesar de Graziano (1959) não incluir em seu quadro comparativo a Prosa após a Poesia na classificação de Hegel, no livro "Curso de Estética: o Sistema das Artes", a Prosa está contida no capítulo terceiro, que trata "A Poesia".

É notório que as Artes se dividem de forma absolutamente diferentes nas classificações de Bacon e Hegel. E, ainda que a Poesia assuma um papel relevante para ambos, isto ocorre de forma distinta. Bacon a utiliza como classe intermediária na progressão do conhecimento, sendo responsável por compreender as experiências da História transmitindo-as para a Filosofia. Em sua classificação, as Artes mecânicas e liberais ficam dispersas e distantes desta função mediadora. Já Hegel, sem pretender classificar o conhecimento, vê a Poesia como a arte mais elevada por sua proximidade com o Espírito, inserindo-a como o último gênero de seu Sistema, que se trata de "um 
processo dialético a partir do qual os principais [...] [gêneros da arte], começando pela arquitetura e terminando com a poesia, se interrelacionam, levando em conta características de sua espácio-temporalidade" (DUARTE, 2016, p. 5).

\subsection{A Classe Belas Artes de Harris}

Em seu quadro comparativo, Graziano (1959) expõe a classe Arte de Harris (Figura 5) conforme retirada de seu artigo "Book Classification", de 1870, no qual o autor apresenta seu sistema de classificação, elaborado especificamente para organização de livros em bibliotecas:

Figura 5 - Classe Arte de Harris. Extrato da comparação de Graziano

\begin{tabular}{|l|}
\hline \multicolumn{1}{|c|}{ 64. (B) Arte } \\
\hline 65. XII. Belas Artes \\
a. Arquitetura \\
b. Escultura \\
c. Desenho e Pintura \\
d. Gravura e Litografia \\
e. Imagens \\
f. Música \\
66. XII. Poesia \\
69. XVI Prosa Ficcional \\
\hline
\end{tabular}

Fonte: Harris (1870); Graziano (1959).

William Torrey Harris atuou, entre os anos de 1868 a 1880, como superintendente de St. Louis Public Schools e responsável pela rede de bibliotecas das escolas públicas daquela cidade (WIEGAND, 1998). Harris (1870) afirma que todo esquema de classificação tem como base um sistema filosófico e declara fazer uso das ideias formativas de Bacon no que propõe. Isto é, em seu esquema, o autor não aplica integralmente o mapeamento dos saberes idealizado por Bacon, pois o considera inapto a atender questões específicas da classificação de livros, dado que não foi criado para tal.

Ao diferenciar a classificação das ciências e a classificação de livros, Harris defende que as demandas não são as mesmas para ambas, pois a ciência tem em seu domínio toda existência e, em certo grau, pode ser classificada por seu assunto-objeto, já os livros podem abordar, de uma só vez uma ou mais fases do assunto. Todavia, apesar de um esquema de 
classificação das ciências não atender as necessidades impostas na organização de livros em uma biblioteca, pode sim oferecer base filosófica para um sistema com essa finalidade.

Desta maneira, Harris (1870, p. 115 , tradução nossa) utiliza na construção de sua classificação "a distinção fundamental de Bacon [...] das diferentes faculdades da alma [...] Memória, Imaginação e Razão, a partir da qual se realizam os três grandes departamentos de aprendizagem humana, a saber: História, Poesia e Filosofia". O autor assegura que, apesar de Bacon não ter a intenção de classificar livros, "[...] seu olhar profundo capturou a ideia formativa que distingue as diferentes espécies de livros".

Harris (1870, p. 117-118, tradução nossa) chama a atenção para mais um fator que impossibilita o uso de forma plena do esquema proposto por Bacon, sua obsolescência em relação ao pensamento vigente no século XIX. Como exemplo, menciona que à época de Bacon "[...] a prosa ficcional tinha se desenvolvido muito pouco, [...] consequentemente, Bacon escolheu o nome Poesia para todo o domínio". Já no século XIX, "[...] o domínio [...] da Fantasia ou Imaginação Produtiva é chamado Arte ou Estética. A derivação da palavra Poesia, Poieo [...] contendo significado criativo admiravelmente adaptado para nomear as obras da Imaginação Produtiva".

Apesar da inaptidão do sistema de Bacon para classificação de livros, Harris defende seu princípio de divisão como verdadeiro e alega que para aplica-lo em uma biblioteca "[...] é necessário não perder de vista seu espírito, nos detalhes que Bacon dá. Verifica-se que em divisões e seções menores, o conteúdo exerce uma influência predominante sobre a classificação, enquanto nas divisões principais a forma é o princípio orientador" (HARRIS, 1870, p. 119, tradução nossa).

As mudanças de pensamentos filosóficos levaram Harris (1870, p. 119, tradução nossa) a adaptar as divisões de Bacon ao seu tempo, iniciando pela inversão da ordem por ele proposta. Ao que Bacon ordena História-PoesiaFilosofia, Harris estabelece Ciência-Arte-História. A Ciência ocupa o lugar da Filosofia e vem em primeiro lugar fornecendo "[...] o método e os princípios para o que se segue". 
I. CIÊNCIA dá o departamento de livros em que o sistema consciente prevalece; II. ARTE (Estética) dá o departamento onde a "unidade orgânica" ou sistema inconsciente prevalece; III. HISTÓRIA dá o departamento onde o sistema é determinado pelas relações acidentais, como tempo e lugar. (HARRIS, 1870, p. 119, tradução nossa).

Enfim, tratando-se da divisão principal Arte, Harris (1870, p. 123, tradução nossa) estabelece o seguinte desdobramento em seu sistema de classificação:

I. Belas Artes

II. Poesia

III. Prosa ficcional

IV. Miscelânea literária, composta por obras retóricas (orações) e ensaios literários que têm uma forma de arte mais ou menos impura, ou estão tão relacionados com obras de arte em seu assunto-objeto que não se separam da classe.

$E$, especificamente na classe Belas Artes, observa-se a subdivisão descrita acima, na Figura 5.

Através deste recorte temático da Arte, identifica-se a expansão da classificação de Harris em relação ao sistema de Bacon - o qual diz se basear. O autor não apenas reúne os gêneros artísticos sob a classe Belas Artes, como insere a Poesia e a Prosa dentro da divisão principal Arte, como propôs Hegel, conforme mostra a Figura 6.

Figura 6 - Comparação dos esquemas de Hegel e Harris

\begin{tabular}{|l|l|}
\hline $\begin{array}{c}\text { Sistema das Artes de } \\
\text { Hegel }\end{array}$ & $\begin{array}{c}\text { Classificaçãobibliográfica de } \\
\text { Harris }\end{array}$ \\
\hline Belas Artes & 65. XII. Belas Artes \\
& a. Arquitetura \\
1. Arquitetura & b. Escultura \\
2. Escultura & c. Desenho e Pintura \\
3. Pintura & d. Gravura e Litografia \\
4. Música & e. Imagens (coleções) \\
5. Poesia & f. Música \\
& XII. Poesia \\
& 69. XVI ProsaFiccional \\
\hline
\end{tabular}

Fonte: Graziano (1959). Adaptado pelos autores.

Desta forma, ainda que a filosofia hegeliana não seja mencionada por Harris em nenhum momento de suas considerações, sua proximidade com o filósofo torna-se visível pelo conteúdo que compõe sua classe Artes, com divisões claramente extraídas do Sistema elaborado por Hegel, conforme sugerido por Graziano (1959). 
A fim de fortalecer sua justificativa, Graziano (1959) agrega outros fatores como o fato de Harris ser hegeliano por admissão e profissão, tendo estudado esta filosofia de 1858 a 1879 , tornando-a base de todas as suas atividades. Isto teria levado Harris a agir sob influência de Hegel, mesmo quando, em seu artigo, admite como verdadeiro o princípio da divisão de Bacon, baseado tanto na forma quanto no conteúdo.

\section{O PENSAMENTO HEGELIANO NA CDD}

Para sustentar sua proposição e negar a influência de Bacon sob a classificação de Harris, Graziano utiliza a classe Belas Artes de maneira, podese dizer, esclarecedora. A presença de Hegel torna-se incontestável em Harris quando são expostas as divisões das classes de ambos os filósofos. Finalmente, como consequência do sistema de Harris, a CDD apresenta sua face hegeliana (Figura 7).

Figura 7 - Aproximação da classe Artes de Bacon, Hegel, Harris e Dewey

\begin{tabular}{|c|c|c|c|}
\hline $\begin{array}{c}\text { Classificação de } \\
\text { Bacon } \\
\text { As manifestações } \\
\text { da Arte presentes } \\
\text { no sistema }\end{array}$ & $\begin{array}{l}\text { Sistema das } \\
\text { Artes de } \\
\text { Hegel } \\
\text { Belas Artes }\end{array}$ & $\begin{array}{l}\text { Classificação } \\
\text { bibliográfica de } \\
\text { Harris } \\
\text { 65. XII. Belas } \\
\text { Artes }\end{array}$ & $\begin{array}{l}\text { Classificação Decimal de } \\
\text { Dewey - } 23^{a} \text { ed. } \\
\text { Classe } 700 \text { e } 800\end{array}$ \\
\hline \multirow{5}{*}{$\begin{array}{c}\text { Poesia } \\
\text { A. Narrativa ou } \\
\text { Heroica (Épica) } \\
\text { B. Dramática } \\
\text { C. Alegórica. } \\
\text { Fábulas, Mitologias, } \\
\text { etc. }\end{array}$} & 1. Arquitetura & a. Arquitetura & $\begin{array}{l}710 \text { Planejamento de área e } \\
\text { arquitetura paisagística } \\
720 \text { Arquitetura }\end{array}$ \\
\hline & 2. Escultura & b. Escultura & $\begin{array}{l}730 \text { Escultura e artes } \\
\text { relacionadas }\end{array}$ \\
\hline & \multirow{3}{*}{ 3. Pintura } & $\begin{array}{l}\text { c. Desenho e } \\
\text { Pintura }\end{array}$ & $\begin{array}{l}740 \text { Artes gráficas e } \\
\text { decorativas } \\
750 \text { Pintura }\end{array}$ \\
\hline & & $\begin{array}{l}\text { d. Gravura e } \\
\text { Litografia }\end{array}$ & 760 Gravuras e impressões \\
\hline & & $\begin{array}{l}\text { e. Imagens } \\
\text { (coleções) }\end{array}$ & 770 Fotografia \\
\hline \multirow{2}{*}{$\begin{array}{l}\text { Filosofia } \\
\text { C. Filosofia humana } \\
\text { (d) Voluptuária } \\
\text { (Artes Liberais) } \\
\text { (1) Pintura } \\
\text { (2) Música }\end{array}$} & 4. Música & f. Música & $\begin{array}{l}780 \text { Música } \\
790 \text { Artes performáticas e } \\
\text { recreacionais }\end{array}$ \\
\hline & 5. Poesia & $\begin{array}{l}\text { XII. Poesia } \\
\text { 69. XVI Prosa } \\
\text { Ficcional }\end{array}$ & 800 Literatura e retórica \\
\hline
\end{tabular}

Fonte: GRAZIANO (1959); DEWEY (2011). Adaptado pelos autores. 
O reflexo da lógica de Harris, inspirada em Hegel, na classificação de Dewey, é claro. Possivelmente o motivo de Dewey, assim como Harris, não mencionar Hegel em seus escritos, se deva ao fato da lógica baconiana já ter alcançado amplo reconhecimento acadêmico à época de Harris e Dewey, diferente da lógica hegeliana. O raciocínio seguido no sistema de Dewey apresenta nas classes 700 e 800 o movimento que vai das artes mais concretas para as mais abstratas, iniciando pela Arquitetura e finalizando com a Poesia, como preferia Hegel.

A abordagem de Dewey reflete as presunções ontológicas e epistemológicas da filosofia ocidental do século em que viveu, apresentando os valores da cultura europeia e norte-americana (OLSON, 2001). Dewey determinou o arranjo e o conteúdo das disciplinas de sua classificação de acordo com o regime de verdade de seu tempo, o mesmo de Hegel e Harris. As artes são representadas por Bacon de maneira dispersa em seu sistema, porque, à sua época, século XVII, o entendimento de Arte não era o mesmo do século XIX.

Apesar do esforço de Graziano, o pensamento baconiano existente em Harris não pode ser absolutamente descartado, ainda que a presença de Hegel seja inegável. Ou seja, é possível que tanto Bacon quanto Hegel tenham proporcionado bases teóricas para elaboração da classificação de Harris.

Ao propor a análise da classe Artes nos três esquemas classificatórios de Bacon, Hegel e Harris - Graziano (1959) estabelece uma comparação entre três perspectivas distintas. Bacon cria seu esquema filosófico para classificar as ciências, no século XVII; Hegel propõe uma classificação que capte a unidade orgânica e plasticidade dialética das Artes, no século XIX; e Harris elabora um sistema para organização de livros, no mesmo século que o anterior. Tais esquemas podem possuir, portanto, uma estruturação diferente, de acordo com suas funções e épocas em que foram elaborados.

Harris declara fazer uso das ideias formativas de Bacon no esquema que propõe - demarcando as divisões principais que distinguem as diferentes espécies de livros -, mas não esclarece a influência que o direciona quanto ao conteúdo, responsável por alimentar as divisões e seções menores. Graziano 
(1959) proporciona esta resposta ao abordar em seu artigo a classificação das Artes, que se apresenta como retrato do Sistema das Artes de Hegel. Olson (2001) corrobora este pensamento e menciona que para elaborar seu sistema, Harris interpretou a dialética epistemológica de Bacon e o modelo ontológico da lógica de Hegel.

A Poesia, é a classe intermediária em Bacon, ocupa no esquema de Harris a mesma posição, todavia aparece acompanhada das Belas Artes, seguindo a mesma ordenação estabelecida por Hegel. Assim como Harris aponta que, no tempo de Bacon, século XVII, a prosa havia se desenvolvido muito pouco e por isso não é mencionada, também as outras Artes não poderiam ocupar o mesmo lugar que dominam na classificação de Harris, século XIX, ficando divididas no sistema de Bacon.

A classe mediana, que para Bacon está ligada à imaginação e para Harris ao sistema inconsciente, conforme afirmam, no esquema de Harris não se limita apenas às palavras, isto é, à Poesia. Percebe-se que as Artes no sistema de Hegel, e consequentemente no de Harris, progridem da menor proximidade que possuem com o espírito para a maior, implicando em uma menor participação do sensível.

O reflexo do pensamento baconiano em Harris está na formação da ideia de conhecimento com base nas faculdades mentais do homem. $O$ objetivo de Bacon era estruturar um método do conhecimento, e suas divisões principais agem como formas de conhecimento. Para o filósofo, a forma é o caminho para alcançar o conhecimento. Por sua vez, o pensamento idealista de Hegel 'focado no 'como' e no 'processo', talvez tenha encontrado na interpretação de Harris o diálogo para a concepção Baconiana de 'forma' e 'forma de conhecimento'" (SALES; PIRES, 2017, p. 3, tradução nossa).

\section{CONSIDERAÇÕES FINAIS}

A afirmação de Graziano (1959), de que o arranjo das Artes na classificação de Harris não seria baseado na classificação do conhecimento proposta por Bacon, mas sim pela divisão das Artes realizada por Hegel, 
reabre discussões teóricas que contribuem diretamente para questões de ordem histórica no universo biblioteconômico, visto que o sistema de Harris é uma das portas de entrada para os estudos de classificações bibliográficas no século XIX. O presente artigo teve como ponto de partida a afirmação de Graziano (1959) e procurou trazer à tona o questionamento revelado pelo pesquisador norte-americano, de modo a contribuir para a pesquisa na área das classificações no Brasil, visto que nos Estados Unidos, notadamente com Graziano e Olson (2011), a influência de Hegel já mostra sua presença.

O foco esteve aqui voltado para a subdivisão da classe Artes nas classificações examinadas. Pôde-se constatar que, embora tenha declarado sua base baconiana ao elaborar seu sistema, Harris não enunciou explicitamente que suas divisões foram fundamentalmente orientadas pela lógica hegeliana. Tal orientação fica clara no fato de que Harris parece ter dado muito mais ênfase ao movimento que vai das artes mais concretas para as mais abstratas, iniciando pela Arquitetura e finalizando com a Poesia, como preferia Hegel, do que privilegiando a função mediadora das artes espalhadas em diversos pontos da classificação de Bacon. Isto é, Harris tomou como ponto de partida as ideias formativas de Bacon para a macroestruturação de sua classificação, organizando-a com base nas faculdades de MemóriaImaginação-Razão, mas sua ordenação interna, ou melhor, o desdobramento de seu arranjo conceitual, deu-se essencialmente com base na divisão de Hegel.

Ao desenvolver sua classificação de livros, Harris conseguiu unir duas perspectivas bastante distintas que sequer tinham a proposta de classificar livros. A perspectiva indutiva de Bacon, que tinha como pretensão dar ordem aos saberes produzidos pela humanidade, deu vez a uma dialética empirista que deixava às artes um papel mediador que ligaria a memória e a razão. Bacon fez isso em um período em que a História parecia estar muito mais consolidada como forma de saber do que a própria Ciência. Hegel, por sua vez, trouxe uma perspectiva racionalista fomentadora de uma dialética idealista encabeçada pela razão (pela Ciência e pela Filosofia) no intuito de compreender o processo do saber, do conhecimento. 
Bacon está presente na classificação de Harris na definição das três grandes classes - História-Poesia-Filosofia -, ao passo que Hegel está fundamentalmente na ordenação dessas classes - Ciência-Arte-História - e nas subdivisões das artes, da mais concreta (mais sensível) à mais abstrata (mais essencial). Assim, não é descabido afirmar que a classe Arte em Harris se aproxima sensivelmente da categoria Essência de Hegel. Desse modo, não cabe aqui concordar integralmente com Graziano e afirmar que a classificação de Harris "vira as costas" para a lógica de Bacon e se aproxima exclusivamente da lógica de Hegel. Prefere-se aqui entender que Harris conseguiu a proeza de unir filosofias distintas para o universo biblioteconômico das classificações. No entanto, dada a visível convergência entre a classificação de Harris e a divisão proposta por Hegel, entende-se que a alegação de Graziano presta um favor relevante aos estudos das classificações bibliográficas, transferindo a esses a responsabilidade de inserir Hegel no ensino e pesquisa da área.

\section{REFERÊNCIAS}

ANJOS, Liane dos. Sistemas de classificação do conhecimento na Filosofia e na Biblioteconomia: uma visão histórico-conceitual crítica com enfoque nos conceitos de classe, de categoria e de faceta. 2008. $291 \mathrm{f}$. Tese (Doutorado em Ciência da Informação) - Escola de Comunicação e Artes da Universidade de São Paulo, São Paulo, 2008.

BACON, Francis. Novumorganum. 2002. Disponível em: http://www.ebooksbrasil. org/adobeebook/norganum.pdf . Acesso em: 11 jan. 2018.

. O progresso do conhecimento. Tradução Raul Fiker. São Paulo: UNESP, 2007. Título original: The Proficience and Advancement of Learning Divine and Humane (1605).

BARBOSA, Alice Príncipe. Teoria e prática dos sistemas de classificação bibliográfica. Rio de Janeiro: Instituto Brasileiro de Bibliografia e Documentação, 1969. Obras Didáticas, 1.

BRAS, Gérard. Hegel e a arte: uma apresentação à Estética. Tradução de Maria Luiza X. de A. Borges. Rio de Janeiro: Jorge Zahar, 1990. (Textos de Erudição e Prazer).

DUARTE, Rodrigo. Do sistema das artes à ambiência pós-histórica: itinerários da estética contemporânea. Viso - Cadernos de estética aplicada: revista eletrônica de estética, v. 10, n. 19, jul./dez. 2016. Disponível em: 
http://www.revistaviso.com.br/pdf/Viso_19_Rodrigo Duarte.pdf. Acesso em: 12 jan. 2018.

EATON, Thelma. The development of classification in America. 1959.

Disponível em:

https://www.ideals.illinois.edu/bitstream/handle/2142/1474/Eaton830.pdf?seque nce=2\&isAllowed=y. Acesso em: 20 maio 2017.

FOSKETT, A. C. A abordagem temática da informação. São Paulo: Polígono; Brasília: Ed. Universidade de Brasília, 1973.

GRAZIANO, Eugene E. Hegel's philosophy as basis for the Dewey Classification Schedule. Libri, v. 9, p. 45-52, 1959.

HARRIS, WM. T. Book classification. The Journal of Speculative Philosophy, St. Louis, v. IV, p. 114-128, 1870.

HEGEL, G. W. F. Curso de Estética: o Sistema das Artes. Tradução Álvaro Ribeiro. São Paulo: MartinsFontes, 1997. Título original: Vorlesungenüber die Ästhetik (1835).

KELLER, Phillip Wilhelm. Estrutura da obra de arte na filosofia de Hegel: análise da estrutura da arte nos cursos de Berlim com relação aos conceitos de organismo, ação e conceito. 2011. 129 p. Tese (Doutorado em Filosofia) Faculdade de Filosofia, Letras e Ciências Humanas, Universidade de São Paulo, São Paulo, 2011. Disponível em:

http://www.teses.usp.br/teses/disponiveis/8/8133/tde-17082012-104854/ptbr.php. Acesso em: 18 jan. 2018.

LA MONTAGNE, L. E. American library classification: with special reference to the Library of Congress. Handen: The Shoe String Press, 1961.

LEIDECKER, K. F. Yankee teacher: the life of William Torrey Harris. New York: The Philosophical Library, 1946.

MILLS, J. A morden outline of library classification. London: Chapman and Hall, 1960.

OLSON, Hope A. A potência do não percebido: Hegel, Dewey e seu lugar na corrente principal do pensamento classificatório. InCID: R. Ci. Inf. e Doc., Ribeirão Preto, v. 2, n. 1, p. 3-15, jan./jun. 2011. Disponível em: http://www.revistas.usp.br/incid/article/view/42331. Acessoem: 20 maio 2017.

Sameness and difference: a cultural foundation of classification.

Library Resources\&Technical Services, Chicago, v. 45, n. 3, p. 115-122, jul. 2001. Disponível em:

http://polaris.gseis.ucla.edu/gleazer/462_readings/olson_2001.pdf. Acesso em: 20 maio 2017.

PIEDADE, M. A. Requião. Introdução à Teoria da Classificação. 2. ed. rev. e aum. Rio de Janeiro: Interciência, 1983. 
POMBO, Olga. O enciclopedismo romântico: Novalis e Hegel. Lisboa, 2002. Disponível em: http://www.educ.fc.ul.pt/hyper/enc/cap3p7/romantico.htm. Acesso em: 13 jan. 2018.

ROSSI, Paolo. Francis Bacon: da magia à ciência. Tradução Aurora Bernardini. Londrina: Eduel; Curitiba: UFPR, 2006.

SALES, Rodrigo de; PIRES, Thiago Blanch. The classification of Harris: influences of Bacon and Hegel in the universe of library classification. VI North American Symposium on Knowledge Organization (NASKO, 2017). Proceedings... Champaign, IL. Universityof Illinois, 2017. Disponível em: http://www.iskocus.org/NASKO2017papers/NASKO2017_paper_5.pdf. Acesso em: 16 ago. 2017.

SANTORO, Fernando. Sobre a estética de Aristóteles. Viso: Cadernos de estética aplicada, v. 1, n. 2, p. 1-13, maio/ago. 2007. Disponível em: http://revistaviso.com.br/visArtigo.asp? sArti=12. Acesso em: 31 maio 2018.

SAYERS, W. C. B. An introduction to library classification. 9. ed. Londres: Grafton, 1955.

SHIRAYAMA, Cristiane de Melo. Francis Bacon e O Progresso do Conhecimento no Início do Século XVII. 2016. 89 p. Dissertação (Mestrado em Filosofia) - Escola de Artes, Ciências e Humanidades, Universidade de São Paulo, São Paulo, 2016. Disponível em: http://www.teses.usp.br/teses/disponiveis/100/100135/tde-10102016182510/en.php. Acesso em: 18 jan. 2018.

SIQUEIRA, Jéssica Câmara. O conceito classificação: uma abordagem histórica e epistemológica. Revista Brasileira de Biblioteconomia e Documentação, Nova Série. São Paulo, v. 6, n. 1, p. 37-49, jan./jul. 2010.

VICKERY, Brian C. Classificação e indexação nas ciências. Rio de Janeiro: BNG/Brasilart, 1980. Tradução de M.C.G. Pirolla.

WIEGAND, Wayne A. The "Amherst Method": the origins of the Dewey Decimal Classification Scheme. Libraries\&Culture, v. 32, n. 2, p. 175-194, spring 1998.

\title{
PHILOSOPHY'S MIRROR: HEGEL'S PRESENCE IN HARRIS AND DEWEY CLASSIFICATIONS
}

\begin{abstract}
Introduction: Created in the nineteenth century, the Dewey Decimal Classification (DDC) carries in its unchanging hierarchical structure the thoughts of its time. Among the various sources that contributed to its conception, William Torrey Harris is recognized in the Knowledge Organization literature as Dewey's most immediate influence to create your system. The article published in 1959 by Graziano, points to hegelian's thought as the true philosophical support of Harris's scheme and,
\end{abstract}


consequently, for Dewey Decimal Classification, questioning the place occupied for Bacon in this systems. Objectives: The purposes of this research were analyzes the philosophical influences that based the classification of Arts in Harris and Dewey schemes, remaking Graziano's steps, in order to check the plausibility of his statement and extend his discussion, making progress in the DDC theoretical studies. In this article, it is proposed to examine the understanding of Art that formed the classifications of Bacon, Hegel, Harris and Dewey. Methodology: The methodological approach adopted as background was the historical-structural dialectics, which was used in order to develop an explanatory and qualitative investigation, considering the analysis of four different classifications. Results: The results presented clearly indicate Hegel's presence not explicitly assumed by Harris and Dewey in their systems and still little discussed in the representation information field in Brazil. Conclusions: It is concluded, unlike Graziano, that it is not possible to completely remove Baconian's thought from the structure of Harris's bibliographic classification, however, the presence of Hegel really confirms itself as the feeder source of the Arts class content.

Descriptors: Knowledge Organization. Classification. Arts.

\title{
ESPEJO DE UNA FILOSOFÍA: LA PRESENCIA DE HEGEL EN LAS CLASIFICACIONES DE HARRIS Y DEWEY
}

\begin{abstract}
RESUMEN
Introducción: Creada en el siglo XIX, la Clasificación Decimal Dewey (CDD) lleva en su estructura jerárquica inmutable los pensamientos de su tiempo. Entre las diversas fuentes que contribuyeron a su concepción, William Torrey Harris es reconocido por la literatura de la Organización del Conocimiento como la influencia más inmediata de Dewey para crear su sistema. El artículo publicado en 1959 por Graziano, señala el pensamiento de Hegel como el verdadero soporte filosófico del esquema de Harris y, consecuentemente, de la Clasificación Decimal de Dewey, cuestionando el espacio de Bacon en estos sistemas. Objetivos: Los propósitos de esta investigación fueron analizar las influencias filosóficas que basaron la clasificación de las artes en los esquemas de Harris y Dewey, rehaciendo los pasos de Graziano, con el fin de comprobar la plausibilidad de su afirmación y extender su discusión, avanzando en los estudios teóricos de la CDD. En este artículo se propone examinar el pensamiento sobre las Artes que formaron las clasificaciones de Bacon, Hegel, Harris y Dewey. Metodología: El enfoque metodológico adoptado como trasfondo fue la dialéctica histórico-estructural, que se utilizó para desarrollar una investigación explicativa y cualitativa, considerando el análisis de cuatro clasificaciones distintas. Resultados: Los resultados presentados indican claramente la presencia de Hegel no asumida explícitamente por Harris y Dewey en sus sistemas y aún poco discutida en el campo de la representación de la información en Brasil. Conclusiones: Se concluye, en oposición a Graziano, que no es posible eliminar completamente el pensamiento de Bacon de la estructura de la clasificación bibliográfica de Harris, sin embargo, la presencia de Hegel se confirma como la fuente que alimenta el contenido de la clase Artes.
\end{abstract}

Descriptores: Organización del Conocimiento. Clasificación. Artes. 